\title{
Fractionation of the Neutral Lipids of Rice-bran Oil by Centrifugal Liquid Chromatography
}

\author{
Hiroyuki Shimasaki and Nobuo Ueta \\ Department of Biochemistry, Teikyo University School of Medicine, \\ 2-11-1 Kaga, Itabashi-ku, Tokyo 173, Japan \\ Received July 22, 1982
}

\begin{abstract}
A centrifugal liquid chromatograph was used to isolate the neutral lipids of rice-bran oil and corresponding model compounds. A rapid, clear-cut separation of the neutral lipids was obtained; the order of elutions was the same as that of liquid column chromatography. This report presents a brief discussion on the use of centrifugal liquid chromatography for the separation of neutral lipids.
\end{abstract}

The silicic acid chromatography of simple and complex lipids has been widely used in chemical and biochemical research on lipids since its early introduction by Borgström, ${ }^{1,2)}$ Barron and Hanahan ${ }^{3)}$ and others. ${ }^{4}$ 7) Adsorption column chromatography has been employed extensively for the fractionation and isolation of lipids, but under the conditions generally employed, the methods require relatively long periods of time. In order to speed up the process, a rotating column, which revolves as a centrifuge with speeds of 100 up to $2000 \mathrm{rpm}$, is described for the fractionation of neutral lipids. The authors present their experience of lipids analysis using the centrifugal liquid chromatograph (Model CLC-5, Hitachi, Japan), inasmuch as the extraordinary potential of this device is not internationally well known. $^{8)}$

\section{MATERIALS AND METHODS}

Materials. Free and esterified sterols, free fatty acids, and triglycerides were purchased from Nakarai Drug Co. (Kyoto, Japan); 1,2-dipalmitin and 1-monopalmitin were obtained from Sigma Chemical Co. (St. Louis, MO). All compounds were checked for purity by one-dimensional thin layer chromatography. Crude rice-bran oil was kindly provided by Dr. A. Kato (Nat. Chem. Lab. for Industry, Ibaragi). All solvents were freshly distilled before use.

Column preparation. The apparatus used in the present study was a Hitachi centrifugal liquid chromatograph model CLC-5 (Hitachi-Koki Ltd., Japan) with a chromatographic column, $300 \mathrm{~mm}$ diameter $\times 3 \mathrm{~mm}$ height. The disk column placed on the apparatus was packed with 45 grams of silica gel (Fuji-KT Gel ${ }^{\circledR}$ ). The adsorbent purchased from Hitachi-Koki Ltd. of Japan, was 200 mesh with an average diameter of $140 \AA$ and pretreatment or activation of the adsorbent was not necessary. The packed column was maintained in continuous operation at 1000 rpm during which it was washed with 20 column volumes of methanol and 20 column volumes of chloroform. Finally, 20 column volumes of hexane were used for neutral lipid analysis. For fractionation of the lipids, the chromatography flow rate was maintained at $15 \mathrm{ml} / \mathrm{min}$.

The best combinations of solvents for fractionation of the neutral lipids from crude rice-bran oils and standard mixtures were 15 percent benzene in hexane, 5 percent diethyl ether in hexane, benzene with acetic acid in hexane (5:1:94), 15 percent diethyl ether in hexane, 30 percent diethyl ether in hexane and 100 percent diethyl ether. Each lipid fraction was quantitatively determined by gravimetric analysis and the purity of the eluents was determined by TLC comparing with pure reference standards. For the determination of fatty acid composition, the lipid classes were interesterified with methanol using $\mathrm{HCl}$ as a catalyst. ${ }^{9)}$ Gas liquid chromatography (GLC) was carried out with a flame ionization detector using a $2 \mathrm{~m} \times 2 \mathrm{~mm}$ column of $12 \%$ EGSS-X at $190^{\circ} \mathrm{C}$ and $\mathrm{N}_{2}$ as the carrier gas.

\section{RESULTS AND DISCUSSION}

Figure 1 shows the typical separation of the reference mixture of major neutral lipids. The combination of solvents for the analysis and the fractions shown in Fig. 1 were $15 \%$ benzene in hexane, cholestryl ester (I); $5 \%$ diethyl ether in hexane, triglyceride (II); a mix- 


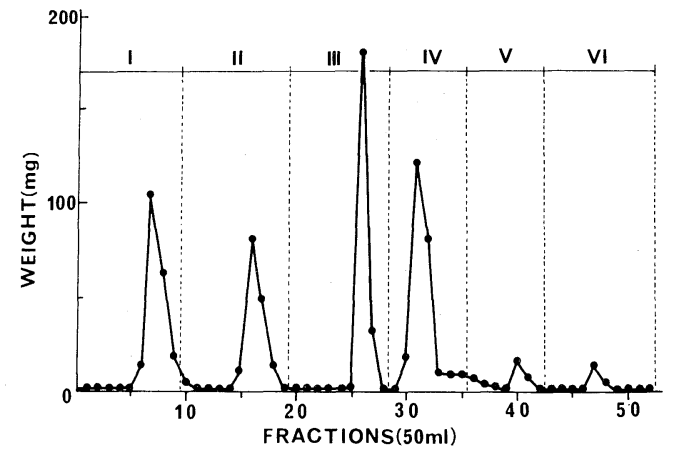

FIG. 1. Chromatogram of Reference Mixture of Neutral Lipids.

I, cholesteryl palmitate; II, triolein; III, stearic acid; IV, cholesterol; V, 1,2-dipalmitin; VI, 1-monopalmitin. Recovery, $107.1 \%$. See text for details of solvents.

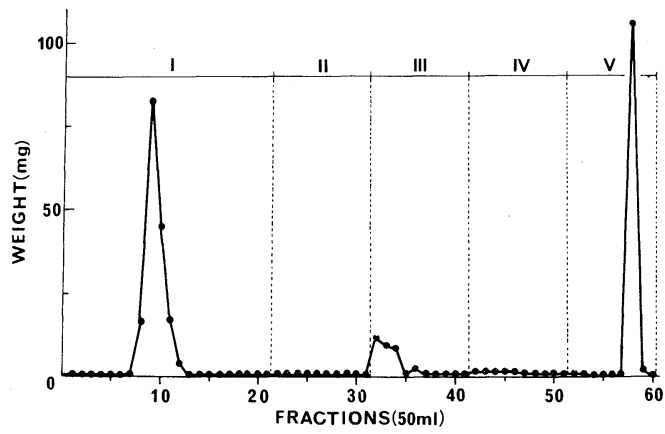

FIG. 2. Chromatogram of Free Fatty Acids.

I, triolein; II, not detected; III $\sim$ V, stearic acid. Solvents were $5 \%$ (I), $15 \%$ (II), 20\% (III) and 50\% ether in hexane (IV), and (V) a mixture of ether-acetic acid-hexane $(10: 1: 90)$.

ture of diethyl ether-acetic acid-hexane $(5: 1$ : 94), free fatty acid (III); $15 \%$ diethyl ether in hexane, cholesterol (IV); 30\% diethyl ether in hexane, 1,2-diglyceride (V); and 100\% diethyl ether, 1-monoglyceride (VI). A single lipid was detected by TLC analysis at the peak in each fraction.

Stearic acid, which was the standard for free fatty acids, was eluted as a single peak by the solvent system of $5 \%$ diethyl ether in hexane containing $1 \%$ acetic acid. This fatty acid, however, was not eluted by $5 \%$ diethyl ether in hexane without acetic acid, or even if the content of diethyl ether in hexane was increased to $50 \%$ as shown in Fig. 2. The peak of

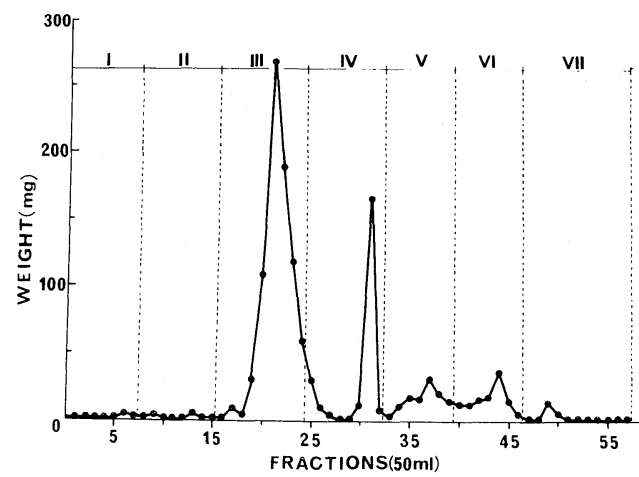

FIG. 3. Chromatogram of Crude Rice-bran Oils.

Major neutral lipids in fractions are: I, hydrocarbons; II, sterol esters; III, triglycerides; IV, free fatty acids; $\mathbf{V}$, free sterols; VI, diglycerides; VII, monoglycerides. Solvents were hexane (I), $15 \%$ benzene in hexane (II), $5 \%$ ether in hexane (III), $5 \%$ ether in hexane with $1 \%$ acetic acid (IV), $15 \%$ ether in hexane (V), $30 \%$ ether in hexane (VI) and $100 \%$ ether (VII).

fraction III in Fig. 2 was detected as stearic acid by GLC analysis. The results indicate that free fatty acids may be partially eluted from the column by $20 \%$ diethyl ether in hexane, but the solvent system did not work completely for the elution of fatty acids without acetic acid. The characteristic of this adsorbent in the column was similar to Florisi ${ }^{\circledR}$, which eluted fatty acids in the solvent system of $4 \%$ acetic acid in diethyl ether as described by Carroll. $\left.{ }^{4}\right)$

Preliminary results of the application of the technique to analysis of the lipid classes of crude rice-bran oils are shown in Fig. 3. The peaks of components in the chromatograms were identified on the basis of the retention time of authentic standard lipids and from a consideration of the composition of the eluting solvents. $^{3,4)}$ Trace amounts of hydrocarbons and sterol esters were detected in fractions I and II, respectively. Triglycerides, the major component of this oil, were eluted in fraction III, with $5 \%$ diethyl ether in hexane. Free fatty acids were eluted in fraction $\mathbf{I V}$, as a single peak, but there was some contamination of sterols with free fatty acids. Diglycerides and monoglycerides were eluted with $30 \%$ diethyl ether in hexane and $100 \%$ diethyl ether, respectively. 
The results of this study indicate that a centrifugal liquid chromatograph could be used to separate classes of neutral lipids in the same way as the liquid column chromatography of silicic acid. The disk column on the aparatus was simple to pack and permitted rapid flow rates which could be controlled by the revolution speed of the column. Centrifugal liquid chromatography, as demonstrated in these preliminary studies, should be useful for fractionation of the lipid classes of crude oils and lipid mixtures from other sources.

Acknowledgment. The authors thank Professor O. S. Privett (The Hormel Institute, University of Minnesota) for valuable advice and critical reading of the manuscript.

\section{REFERENCES}

1) B. Borgström, Acta Physiol. Scand., 25, 101 (1952).

2) B. Borgström, Acta Physiol. Scand., 25, 111 (1952).

3) E. J. Barron and D. J. Hanahan, J. Biol. Chem., 231, 493 (1958).

4) K. K. Carroll, J. Lipid Res., 2, 135 (1961).

5) D. L. Fillerup and J. F. Mead, Proc. Soc. Exptl. Biol. Med., 83, 574 (1953).

6) C. H. Lea, D. N. Rhodes and R. D. Stoll, Biochem. J., 60, 353 (1955).

7) J. M. McKibbin, J. Biol. Chem., 220, 537 (1956).

8) H. Shimasaki and N. Ueta, Proc. Jpn. Conf. Biochem. Lipids, 21, 54 (1979).

9) H. Shimasaki, F. C. Phillips and O. S. Privett, J. Lipid Res., 18, 540 (1977). 